\title{
Establishing Mission Requirements Based on Consideration of Aircraft Operations
}

\author{
Robert A. McDonald* \\ California Polytechnic State University, San Luis Obispo, California 93407 \\ DOI: $10.2514 / 1 . C 031878$
}

\begin{abstract}
The design requirements for a next-generation commercial aircraft can do much to secure its fate as a success or failure. New aircraft are often designed to meet or surpass the capabilities of an existing aircraft they are intended to replace. However, in the case of unconventional aircraft, this could lead to significant overdesign resulting in nonviable concepts. Instead, a method of analyzing observed aircraft use is presented with the intent of establishing a set of requirements based on replacing aircraft utility instead of capability. Two aircraft in the commercial fleet are used as example cases, and launch customers for each aircraft are assumed. Data originating from diverse sources are combined to present a probabilistic representation of aircraft use. The data collected include the payloads carried, ranges flown, and assigned cruise altitudes as well as the field length, elevation, and hot day characteristics of the airports used, and the launch customers' fleet size history. Quantitative and qualitative analyses of the compiled aircraft use data are used to justify a set of requirements for a replacement aircraft, which differ substantially from the established performance of the existing aircraft. New aircraft designed to these requirements are expected to be smaller and less expensive than those designed to the original aircraft's capabilities.
\end{abstract}

\section{Introduction}

A LL aircraft have some inherent mismatch between their capability and their utility, i.e., what they can be used for and what they are used for. One contributor to this mismatch is the design margin and is a consequence of the safe design and operation of a given vehicle. Another contributor to this mismatch is when the operator uses the aircraft in ways that do not meet the designer's expectations. Some of this mismatch can also be caused by the relative cost of various trades in the aircraft design process.

For example, consider an efficient transport aircraft sized to a particular design mission. This mission likely does not require all of the possible fuel volume in the wings; however, making all of the possible volume available as fuel tanks does not significantly penalize the design. Accepting such a trade will result in a vehicle with a very long ferry range, likely a seldom used capability.

When called to replace that transport aircraft, one could set the design requirements to match its capabilities, including the long ferry range. If the new aircraft will use similar but improved technologies, then the resulting design trades will likely have similar costs, resulting in a low cost to meet the ferry range requirement. However, if the new aircraft uses significantly different technologies, then the resulting design trades may have significantly different costs. The seldom used ferry range requirement may be very expensive to the design of an aircraft with poor energy storage density.

One solution to this problem would be to design the replacement aircraft to just the design requirements (not the capabilities) of the original aircraft. However, those design requirements may have been lost or may only be known to the aircraft's manufacturer. In addition, the aircraft may have fallen into a common use significantly different from the original design requirements. The solution presented in this paper is to design the replacement aircraft to match the observed use of the original aircraft.

Presented as Paper 2012397 at the 2012 AIAA Aerospace Sciences Meeting, Nashville TN, 69 January 2012; received 22 March 2012; revision received 13 August 2012; accepted for publication 31 October 2012; published online 15 April 2013. Copyright (C) 2012 by Robert McDonald. Published by the American Institute of Aeronautics and Astronautics, Inc., with permission. Copies of this paper may be made for personal or internal use, on condition that the copier pay the $\$ 10.00$ per copy fee to the Copyright Clearance Center, Inc., 222 Rosewood Drive, Danvers, MA 01923; include the code 1542 3868/13 and \$10.00 in correspondence with the CCC.

*Associate Professor, Aerospace Engineering, One Grand Avenue. Senior Member AIAA.

\section{Background}

The aircraft design process has historically been viewed as starting with a statement of specifications or requirements for a new vehicle $[1,2]$. This mode of operation was largely reinforced by the govern ment acquisition and systems engineering processes [3]. Recent design texts emphasize the importance of questioning the require ments [4], but the process of setting the requirements is generally considered beyond the scope of the aircraft design process.

Proper establishment of the requirements has profound implica tions for the capabilities of the vehicle and its potential for success. Setting the requirements for a complex system reduces the available design freedom and commits a significant fraction of the overall cost at a time when relatively little is known about the eventual design [5]. In the defense sector, there are organizations whose primary purpose is to model, trade, and establish requirements for future vehicles. In the commercial sector, the voice of the customer is critical, but the airframer has the ultimate responsibility for setting the requirements for its future products; setting the requirements well can dominate the conceptual design process []].

In an optimal design problem, active constraints are those requirements that determine the design; from an optimal constrained point, a small change in some variable will result in a solution that violates an active constraint, and an opposite change in that variable will result in a suboptimal solution. Identifying and understanding the active constraints and requirements for a given design is critical to its success. Advanced concepts and technologies can have a dramatic impact on the character of the vehicle; this impact can change which requirements are active and truly drive the aircraft design. When performing aircraft advanced concept or technology studies, the choice of requirements that constrain and guide the design must be considered from a fundamental level.

It can be expected that the capability trade studies performed by militaries and commercial airframers would be very tightly guarded. By definition, these studies make clear the chosen tradeoffs and thereby the strengths and weaknesses of a proposed design. This information has obvious value to any competitor or adversary. Whether because of the sensitive nature or because little academic work has been done in this area, there are very few publications available that discuss how the requirements are set when considering a new vehicle.

One may conceive of many ways to trade and set the requirements for a new commercial aircraft. In an ideal world, the requirements would be traded in an environment that quantified their effect on the aircraft design and its life cycle cost, carrying these calculations through to return on investment. 
This environment would perhaps use a game theory approach to consider not just the aircraft design but the design and composition of the future fleet while including various sociopolitical and economic scenarios as well as various scenarios representing the actions of competitors and partners in the marketplace. Work toward this kind of comprehensive game based environment has been completed by multiple researchers $[7,8]$, but so far, the game theory decisions have been focused on whether and when to enter a market rather than the specific design requirements governing the proposed design.

Likewise, one may conceive of a military analog to this ideal requirements trade environment. Work has been done to simulta neously model the design, technologies, and requirements for a proposed aircraft $[5,9]$; such a model would enable concurrent trade studies through a unified tradeoff environment (UTE). Although developed for military aircraft, the UTE approach should apply to any complex system. Work has also been done to use campaign analysis to arrive at a high level system effectiveness metric for military aircraft [10]; such a metric could play the role for military systems that return on investment plays for commercial systems.

For better or worse, formal trade studies to establish requirements usually remain beyond the scope of the aircraft design process. Although industrial designers working toward major products may be privy to requirements rigorously established by other groups, the academic and research communities usually have no such organiza tion to rely upon.

In lieu of a proper requirements trade study, many design studies start from the perspective of replacing an in service aircraft. The existing aircraft's capabilities, market, and use guide the require ments and assumptions applied to the replacement design. This is frequently a reasonable approach when the replacement aircraft is similar to the in service aircraft. However, when the replacement aircraft under consideration is dramatically different in concept or technology, this approach may inappropriately influence the new design, leading to concepts that are infeasible or unviable.

The approach of this paper is to improve upon replacing a current aircraft's capabilities but to stop short of a true requirements trade study. In this study, data describing the operational use of aircraft are used to establish design requirements based on how in service aircraft have actually been used, not how they could be used. This allows the simplified perspective of replacing an existing aircraft (or class), but it focuses on replacing the aircraft utility, not its capability. This approach is meant to improve the justification used in estab lishing the requirements for unconventional design studies that cannot support a full requirements trade study.

\section{Method}

The general approach of this paper is to start with a data set that describes some segment of aircraft operations. This description will typically include the aircraft type, the operator, and the origin and destination airport codes; it may also include other information such as some measure of the payload or passengers carried. The operations data set is then augmented with information obtained from other related data sets. This augmentation is accomplished by cross referencing both data sets by matching some common identifying information and copying the relevant information to the entries of the operations data set. For example, the origin and destination airport codes in the operations data set can be cross referenced to an airport database to obtain the length of the longest runway at each airport; if the origin and destination airport codes are identified by their Federal Aviation Administration (FAA) code and the airports in the airport database are identified by their International Civil Aviation Organization (ICAO) code, then a third intermediate database must be used to cross reference the databases.

Different identifying information was used to cross reference various data sets as appropriate. For example, (operator fleet size was cross referenced by date), (airport length, elevation, and weather was cross referenced by airport code), and (weather at reporting stations was cross referenced to airports by distance). Imperfect matches while cross referencing the databases can be a source of error, but in general, these errors are easily detected and corrected; these errors typically occur for a small fraction of the overall operations considered.

The result of this cross referencing is a new aircraft operations data set augmented to give a rich description of each flight represented. The flights can then be treated as experimental observations, and characteristics can be plotted as empirical probability distributions. Quantities can be examined in isolation by plotting an empirical cumulative distribution function (ECDF). An ECDF is created by sorting the data set of interest and then plotting it as the abscissa with a normalized index of the observation's order in the set as the ordinate. Two correlated quantities can be examined together by plotting an empirical joint probability density function (EJPDF). An EJPDF is a two dimensional histogram obtained by binning the observations into a set of bins spanning the two quantities of interest. In this paper, the EJPDF histogram is represented on a gray scale in which the darkest areas represent the most frequent regions of operation; the gray scale is adjusted for each plot individually.

Inspection of these ECDF and EJPDF plots leads to quantitative and qualitative insight used for establishing requirements for future aircraft designs. The fraction of flights that fall within some candidate requirement can be read directly from an ECDF. Although the similar fraction cannot be read directly from an EJPDF, given a corre sponding pair of candidate requirements, the fraction of flights within those requirements can easily be calculated by the program used to generate the EJPDF.

\section{Example Aircraft}

For this paper, the capabilities of two aircraft in commercial service were selected for consideration, the Cessna 208 and the Boeing 737 700. A larger, intercontinental aircraft was not selected because the data sets used primarily cover domestic U.S. transport. Similarly, no military aircraft were considered because the data sets used are limited to civilian air transport.

The Cessna 208 is one of the smallest aircraft in regular commer cial operation today; more than 2000 have been built. It is popular for a number of missions including interisland passenger service in Hawaii and the Caribbean, charter passenger and cargo service in Alaska, and regularly scheduled cargo feeder operation by FedEx. The Boeing 737700 is a workhorse of the domestic air fleet and is representative of a wide range of narrow body transport aircraft; more than 1100737 700s have been built.

In this study, aircraft use is further limited to the consideration of particular launch customers; although not necessary, doing so helps limit the scope of this work and clarifies the analysis. The FedEx Corporation will be considered the launch customer for the Cessna 208 replacement. FedEx participated in the development of the dedicated cargo variants of the aircraft and has taken delivery of 300 airframes. Southwest Airlines (SWA) will be considered the launch customer for the Boeing 737700 replacement. Southwest was the launch customer for the 737 300, 737 500, and 737700 aircraft; recently, Southwest was named the launch customer for the planned

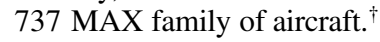

The choice of these particular aircraft and launch customers (and this study in general) was further motivated by the author's interest in studying the possibility of future electric aircraft. The Cessna 208 is a successful commercial aircraft with clear ties to the propeller powered general aviation market, which appears to be the frontier of electric flight. The FedEx feeder operation requires a relatively short range and low daily utilization, providing ample recharge time.

The 737700 is representative of the short haul narrow body aircraft that dominate domestic passenger air transport. Although the electrification of jet transport aircraft does not appear on the near term horizon, it can be expected that smaller, short range aircraft would be among the first candidates considered for replacement. In addition to the aeropropulsive challenges of designing an electric narrow body transport, the daily utilization rate required by Southwest presents a clear challenge to any electric technology.

†ata available online at http://boeing.mediaroom.com/index.php? s 43\&item 2072 [retrieved 22 January 2013]. 


\section{Aircraft Operations Data Sources}

Operational record keeping is a fundamental part of aviation. Every private pilot is directed to log every flight, its conditions, length, number of landings, equipment used, destination, purpose of trip, and anything of note. Thorough operational record keeping extends to the equipment; logs record operations, consumables use, and maintenance of equipment including aircraft, engines, propellers, and avionics. Commercial and military operators undoubtedly compile vast records of the operations of their fleets. Unfortunately, these data are generally not compiled, aggregated, and made available in the open in a way that is useful to the aircraft designer. In this paper, some data sets compiled and made available for other uses are explored as an aid to the aircraft design process.

Some of the data sets used in this study come from nontraditional sources including those informally compiled by loosely knit volunteers (in particular, the OurAirports database and the plane spotting enthusiast fleet size history). These "crowd sourced" data are not collected or audited in any rigorous way; there is no mechanism for accountability in its accuracy. These data sets play a secondary role in this study, and their accuracy is not critical to the method or results presented here. However, where these data sets could be compared to professionally and formally prepared counter parts, their accuracy, completeness, and currency were surprisingly good.

\section{A. Ames Seed Day}

The National Aeronautics and Space Administration (NASA) Airspace Systems Program [11] commissioned the creation of a set of representative air traffic days to support the modeling and simulation of the domestic U.S. air transport network. Actual air traffic data from as flown Enhanced Traffic Management System (ETMS) data were gathered by Metron Aviation [12] and compiled into a set of representative days of high and low volume with good and bad weather. 26 September 2006 was selected as a high volume day with good weather to serve as the "Seed Day" for creation of alternative scenarios. This day includes 84,168 flights over 39 hrs of air traffic for the continental United States; this includes $6 \mathrm{hrs}$ of traffic before the day of interest, $27 \mathrm{hrs}$ of traffic on the day of interest, and $6 \mathrm{hrs}$ of traffic following the day of interest. The day of interest is $27 \mathrm{hrs}$ long because it starts at midnight Eastern and extends to midnight Pacific time.

The Seed Day data include records of every individual flight (takeoff to landing) from the perspective of the air traffic management system; military flights and general aviation visual flight rules (VFR) flights that did not request flight following are not included. The data set includes the operator, equipment used, origin and destination airports, cruise speed and altitude, and route followed. The data do not include any record of the payload (freight/mail/passengers) carried or purpose for the flight.

\section{B. Bureau of Transportation Statistics Database}

The Department of Transportation (DOT) Bureau of Trans portation Statistics (BTS) requires transport operators (truck, ship, rail, and air operators) to report aggregated records of freight, mail, and passengers transported. These data for air transport are readily available from online databases dating back to October 2002 [13].

In this study, the complete segment data set for all carriers for 2009 was used [14]; 2009 was the most recent complete year data set available at the time of this study. The 2009 data set represents more than ten million flights. The DOT uses its own coding system to identify the aircraft type for each data record; cross referencing the aircraft type to other data sets can be problematic in general, but there was no ambiguity in the limited scope cases considered in this study.

The BTS database combines payload and passengers carried into monthly totals for every unique operator, city pair, and equipment combination. Consequently, if a record represents 30 flights, only the average payload values for those flights can be considered; when producing the empirical probability distribution and density plots for those records, 30 identical flights are used. This represents a poten tially significant limitation to the BTS database. In reality, the payload and number of passengers carried on those 30 flights have their own distributions; some flights will carry more than the average, others less.

In the cases considered in this study, the number of flights in any combined record was very small compared to the number of records or the total number of flights represented. Any significant bias introduced by this limitation would be expected to appear as a vertical jump on the corresponding cumulative distribution plot. None of the payload or passenger cumulative distribution plots in this study display such vertical jumps. Nevertheless, this averaging can be expected to weaken the tails of the distributions by bringing those observations toward the average.

\section{Airport Databases}

A number of freely available airport databases were used in this study. By far, the OurAirports [15] database was the most complete, with 43,832 records at the time of access. The OurAirports database is created and maintained primarily through user contributions, though the bulk of entries were obtained by collecting and combining gov ernment supplied information. The OurAirports database includes most general interest information about the airports including latitude, longitude, elevation, and airport identifier; however, the downloadable version does not include the length of the runways at each airport. Various data sources use either the ICAO airport code or the local jurisdiction (say FAA) airport code to identify airports. The OurAirports database contains both kinds of codes where appropriate; this information was used to standardize and convert the airport lookup as required.

The length of the longest runway at as many airports as possible was compiled from three smaller databases. The FAA provides online access to a database of airport data [16]; at the time of access, this database included record of runway length at 19,836 airports. The Airports in Canada web site is maintained by an aviation enthusiast; at the time of access, this database included a record of runway length at 1504 runways. These data were based on official Canadian government information available from NAV CANADA [17,18]. Finally, the avionics company Sandel provides a database of $\overline{11}, \overline{70} 4$ worldwide public airports with runways $2500 \mathrm{ft}$ or longer [19].

\section{National Oceanic and Atmospheric Administration Normal High Temperatures}

Hot day conditions, especially at high elevation airports, can have significant adverse effect on aircraft and engine performance; a typical hot day assumption is $27^{\circ} \mathrm{F}\left(15^{\circ} \mathrm{C}\right)$ above standard day conditions. Each decade, the National Oceanic and Atmospheric Administration (NOAA) publishes a set of climate normals based on recordings from U.S. National Weather Service (NWS) stations [20]. Climate normals are 30 year averages of various weather metrics. The data published by NOAA include monthly average high temperature normals, i.e., the 30 year average of the average daily high temperature for each month. This study focused on the highest such monthly average (typically July), here denoted $T_{30}$.

The increment of this hottest month high temperature average for each weather station over standard day conditions at the same elevation was calculated and denoted $\Delta T_{30}$. This temperature increment was then used to calculate the corresponding hot day density altitude for each airfield. Density altitude is the standard day altitude for which the density is equal to the observed density.

The NOAA temperature normals are provided at 7501 U.S. weather stations. Although many of the NWS stations are likely located at airports, the weather station locations are specified only in terms of the latitude and longitude. The normal high temperature at each airport was approximated as the corresponding temperature at the nearest weather station. Great circle distances between airports and weather stations were calculated based on the World Geodetic System WGS84 ellipsoid. The OurAirports database reports highly precise position data, whereas the NOAA weather stations report

Data available online at http://www.plews.ca/AirportsinCanada.htm [retrieved 30 June 2011]. 


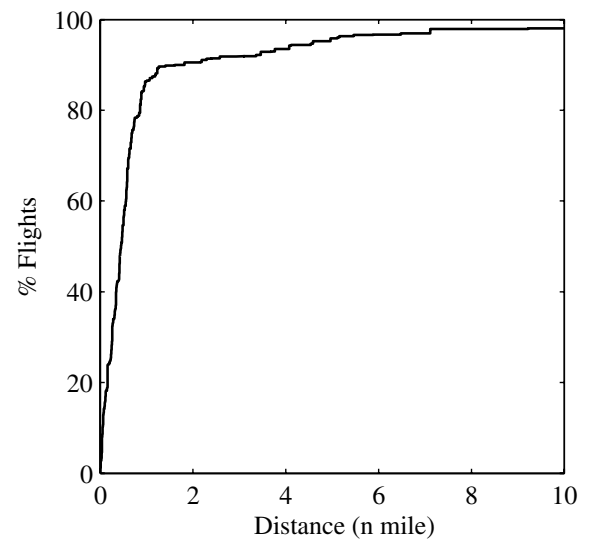

a) For FedEx Cessna 208 operations

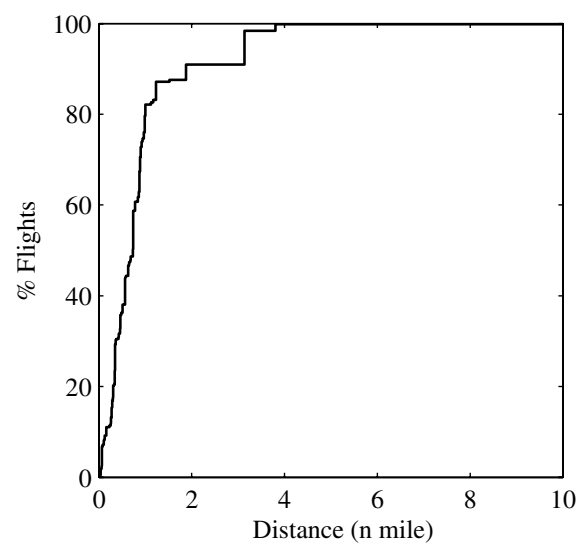

b) For Southwest Airlines 737-700 operations

Fig. 1 Distance from airport to nearest weather station cumulative distribution.

decimal latitudes and longitudes to the nearest minute; this rounding can cause a position error of about $0.7 \mathrm{n}$ miles.

ECDFs of the distance between the nearest weather station and the airports used by each operator are included as Fig. 1. In each case, $90 \%$ of airport operations were within $2 \mathrm{n}$ miles of a weather station. The maximum distance to a weather station for a FedEx Cessna 208 operation was $329 \mathrm{n}$ miles, whereas the maximum distance for a Southwest 737700 operation was $14 \mathrm{n}$ miles, but $99.8 \%$ of operations were within $3.8 \mathrm{n}$ miles of a weather station. The FedEx operations that occurred long distances from the nearest weather station are flights to other Caribbean nations.

\section{E. Operator Annual Reports}

The Securities and Exchange Commission (SEC) requires all publicly traded companies to file an annual report on the financial and operating statistics of the company. Companies use the annual report as an opportunity to reach out to investors, sometimes providing significantly more than the SEC required information. Because a fleet of aircraft represents a significant capital expense and asset, fleet size and composition is often reported in the annual report. The annual reports provided by Southwest Airlines [21 37] include the fleet size and composition as well as a handful of aircraft utilization metrics, which will be discussed later.

The operating statistics reported by the FedEx Corporation [38 40] include the fleet size and composition of their entire air fleet; these data are summarized in Table 1 . In 2010, FedEx operated 252 Cessna 208 aircraft. In general, the number of aircraft of a particular type operated by FedEx is fairly stable. When a new aircraft type is acquired, purchases are spread over a few years. A stable number of aircraft are operated for a number of years until the aircraft are ready for replacement. Transition to a new type is also spread over a few years.

\section{F. Plane Spotting Enthusiasts}

There is a distributed worldwide community of aviation enthusi asts who enjoy plane spotting: the observation, logging, and often photography of aircraft. The internet has provided a means for these enthusiasts to form communities and combine their efforts. In addition to aircraft sightings, plane spotters use aircraft registration, transfer of ownership, accident reports, and any other available information to compile their histories. One small group of plane spotters is working to compile complete service histories of commer cial aircraft [41]. Their data set was used as the basis of building a complete history of Southwest Airlines' fleet; this history includes the $\mathrm{N}$ number, serial number, and date of entry to service and exit from service of every aircraft Southwest has ever flown. Exit from service was sometimes approximated as the date of transfer of ownership or change in registration; consequently, the greatest inaccuracies in this history are at the end of service for aircraft that spent a significant time in storage before being transferred (namely, the old 737200 fleet).
Plane spotters collect some of their information through direct observation, but they largely rely on information made public by manufacturers and regulators. The Boeing Company provides an online database of aircraft orders and deliveries. $\stackrel{\S}{.}$ Although this resource does not provide information on aircraft leases, retirements, or used aircraft purchases, it can provide the basis of an airline fleet analysis.

Figure 2 depicts the complete history of the Southwest Airlines fleet through the end of 2011. The lines are drawn from the combined plane spotting data, plotted at the end of each month. The diamonds reflect the fleet history reported in the company annual reports. The aircraft types are indicated by the FAA designation; 733 represents the 737300 and 737 represents the 737700 . The history includes two brief periods in which Southwest operated a small number of 727200 aircraft here designated 722 .

Southwest's history of continuous growth results in a much more volatile fleet history than for the FedEx Cessna 208. Although the 737300 fleet has an extended period of constant size, purchases were spread over a period of nearly 15 years and only ceased when acquisition of the 737700 started. In the coming years, it is evident that Southwest's continued growth and the advancing age of their 737300 and 737500 aircraft will require a high rate of aircraft acquisition. The 2010 Southwest Airlines Annual Report [37] estimates the useful life of their aircraft and engines at 2325 years.

In this study, the plane spotting enthusiast information was only used to estimate Southwest's fleet size in a given month, which was then used to calculate the daily and yearly aircraft utilization metrics. Interpolation of the year end fleet size reported in the company annual reports would provide an alternative source for this information.

\section{FedEx Cessna 208 Operations}

A number of aircraft utilization metrics were calculated for the fleet of FedEx Cessna 208s. All aircraft operations reported to the BTS in 2009 were combined and divided by the aircraft fleet size reported in the company's annual report. The calculated utilization metrics are summarized in Table 2 . The BTS only requires reporting of transport flights, and so maintenance, training, and repositioning flights do not appear in these utilization metrics. Furthermore, FedEx primarily operates the feeder fleet on weekdays, and so both daily and weekday utilization metrics were calculated as appropriate.

The BTS data include the total payload flown for each record (month, operator, equipment, city pair) as well as the number of flights included in that record. These data were expanded by assum ing that each flight in a record carried the average payload of the record. An ECDF of the payload carried is plotted as Fig. 3a. It is evident that the FedEx Cessna 208 fleet carried less than $1920 \mathrm{lb} 95 \%$ of the time and less than $1500 \mathrm{lb} 66 \%$ of the time.

${ }^{\S}$ Data available online at http://active.boeing.com/commercial/orders/ [retrieved 10 March 2012]. 
Table 1 History of the FedEx fleet

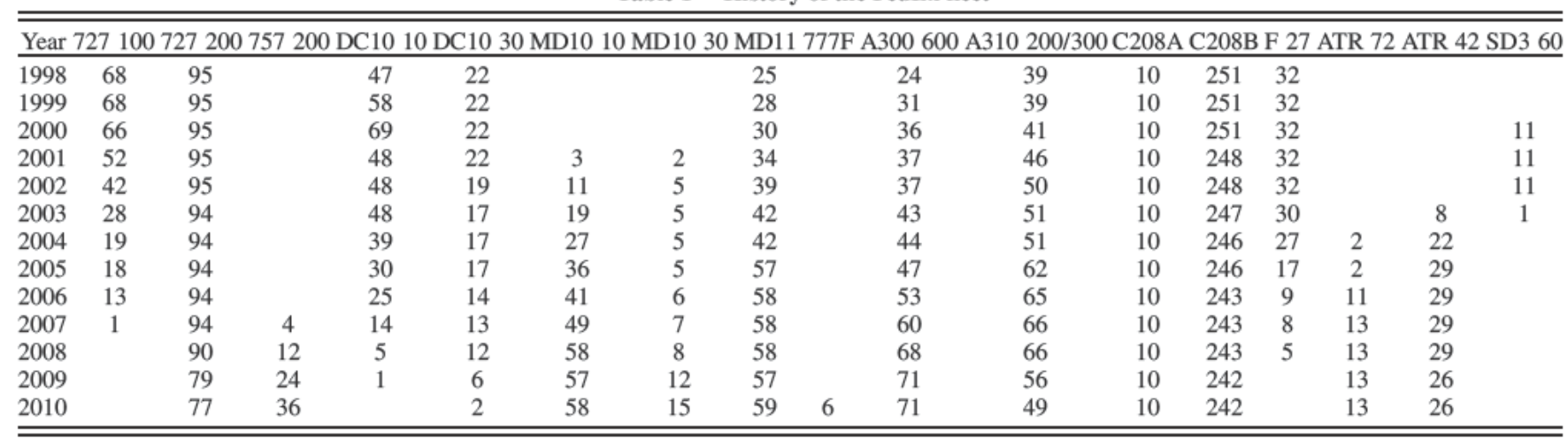

A set of similar ECDFs was constructed to study the distribution of distance flown by the FedEx Cessna 208s. Curves based on both the BTS data and the Seed Day data were plotted as Fig. 3b. Despite the three year separation between the data sets and the dramatic difference between the time period covered (one day vs one year), the curves essentially agree. Based on the more recent BTS data, the FedEx Cessna 208 fleet flew less than $300 \mathrm{n}$ miles $99.5 \%$ of the time and less than $200 \mathrm{n}$ miles $91 \%$ of the time.

The payload/range operation of the FedEx Cessna 208 fleet based on the BTS data is plotted as an EJPDF in Fig. 3c. The advertised payload/range performance for four variants of the Cessna 208 were also included in Fig. $3 \mathrm{c}$ as the solid lines. Despite significantly greater operational capability, the highest densities of Cessna 208 flights are approximately $175 \mathrm{n}$ miles long and carry about $1700 \mathrm{lb}$ of payload.

The flight plan altitude/range operation of the FedEx Cessna 208 fleet based on the Seed Day data is plotted as an EJPDF in Fig. 3d. The highest densities of flights are flown between 5000 and $7000 \mathrm{ft}$ of altitude. Although very short flights are not flown at high altitude, there is no strong trend for longer flights to be flown at high altitude.

The NOAA weather normal data at weather stations nearest the airports used in the 2009 BTS FedEx Cessna 208 operations are plotted in Fig. 4. The hottest normal monthly high temperature at an airport used by FedEx is $112.2^{\circ} \mathrm{F}$. The standard $27^{\circ} \mathrm{F}$ hot day assumption is plotted as a vertical line in Figs. 4b and 4d. Only $37 \%$ of the airport operations have normal high temperatures below the standard $27^{\circ} \mathrm{F}$ hot day assumption. A $40^{\circ} \mathrm{F}$ hot day assumption would include $80 \%$ of the airport operations; a $49^{\circ} \mathrm{F}$ assumption would be required to include $90 \%$ of operations.

The range of airfields used by the FedEx Cessna 208 fleet were explored in Fig. 5. The runway length at airfields used by the BTS flights were obtained from the combined runway length data set. The airfield elevation and runway length are plotted as ECDFs in Figs. $\underline{5 a}$ and $5 \mathrm{~b}$, respectively. The hot day density altitude was also included in Fig. $\underline{\text { 5a. }}$.

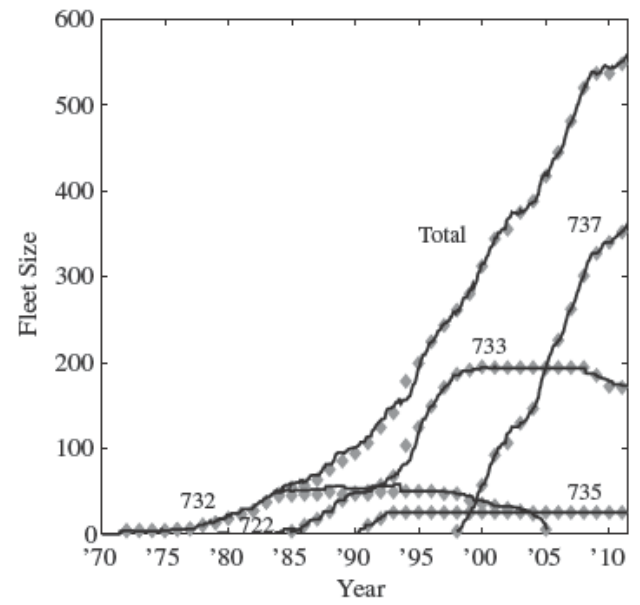

Fig. 2 History of the Southwest Airlines fleet.
Table 2 FedEx 2009 Cessna 208 average aircraft utilization

\begin{tabular}{lcc}
\hline \hline Metric & Value & Units \\
\hline Daily flights & 1.1 & \\
Weekday flights & 1.3 & \\
Yearly flights & 407 & \\
Daily utilization (BTS ramp to ramp) & $1: 09$ & $\mathrm{~h}: \mathrm{m}$ \\
Daily utilization (BTS air time) & 59 & $\mathrm{~m}$ \\
Weekday utilization (BTS ramp to ramp) & $1: 21$ & $\mathrm{~h}: \mathrm{m}$ \\
Weekday utilization (BTS air time) & $1: 09$ & $\mathrm{~h}: \mathrm{m}$ \\
Yearly utilization (BTS ramp to ramp) & 421 & $\mathrm{~h}$ \\
Yearly utilization (BTS air time) & 361 & $\mathrm{~h}$ \\
\hline \hline
\end{tabular}

Although the Cessna 208 is renowned for its short field capability, most of FedEx's operations do not appear to require that level of performance. Most of the airfields used are at a relatively low elevation, with $80 \%$ of flights from fields at less than $2000 \mathrm{ft}$ and $93 \%$ at less than $5000 \mathrm{ft}$. When considering the hot day conditions, the density altitude ECDF shifts as much as $3000 \mathrm{ft}$ from the elevation ECDF, with $80 \%$ of the flights at less than $4400 \mathrm{ft}$ and $93 \%$ at less than $7500 \mathrm{ft}$ density altitude. Most takeoffs and landings occur from relatively long runways; less than $5 \%$ of operations occur from runways less than $5000 \mathrm{ft}$ in length. Most of the short field operations are limited to service in the Caribbean, suggesting the possible use of a subfleet with short field capabilities to service that area. The combined density of the elevation/runway length operation of the FedEx Cessna 208 is plotted as an EJPDF in Fig. 5c; the corresponding density altitude/runway length EJPDF is plotted in Fig. 5d.

\section{FedEx Cessna 208 Replacement Proposed Requirements}

A designer considering the design of a Cessna 208 replacement with FedEx as a launch customer may consider designing the replacement aircraft to a set of requirements less than the Cessna 208's full capabilities. Such a vehicle may be smaller and cheaper than the aircraft it replaces, or the reduced set of requirements may enable consideration of alternative advanced concept aircraft, which may not feasibly be designed to match the Cessna 208's performance in every way.

If similarly sized and operated, FedEx may be reasonably expected to purchase between 250 and 300 replacement feeder aircraft. The FedEx feeder operation demands relatively light aircraft utilization; the aircraft should be able to sustain two flights per day, and if the vehicle cruises at a similar speed, it will accumulate approximately 500 flight hours per year. The vehicle could be designed to carry $2000 \mathrm{lb}$ of payload $300 \mathrm{n}$ miles or, if a more aggressive reduction in capability is required, $1500 \mathrm{lb}$ of payload $200 \mathrm{n}$ miles. No pressurization system is required unless it benefits the concept under consideration. Finally, although the field performance is not likely to be critical, the design airfield could be taken to be $5000 \mathrm{ft}$ long and located at $2000 \mathrm{ft}$ elevation. A $40^{\circ} \mathrm{F}$ hot day assumption brings the density altitude to $4512 \mathrm{ft}$. 


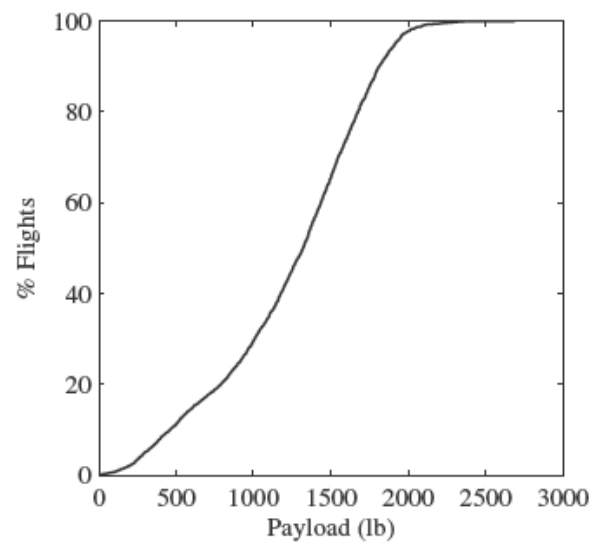

a) BTS payload cumulative distribution

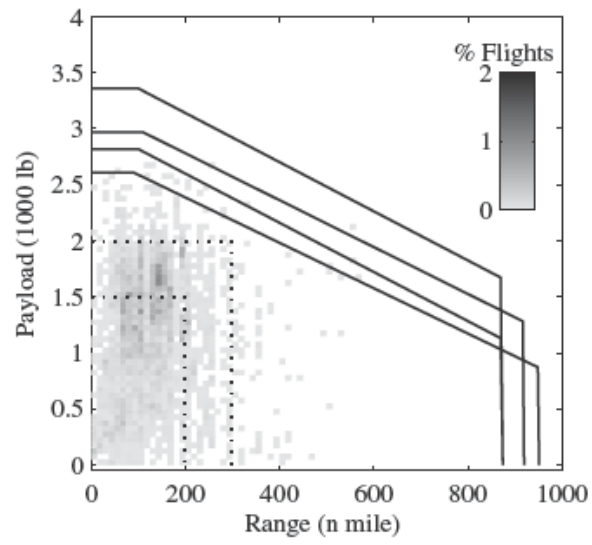

c) BTS payload/range density

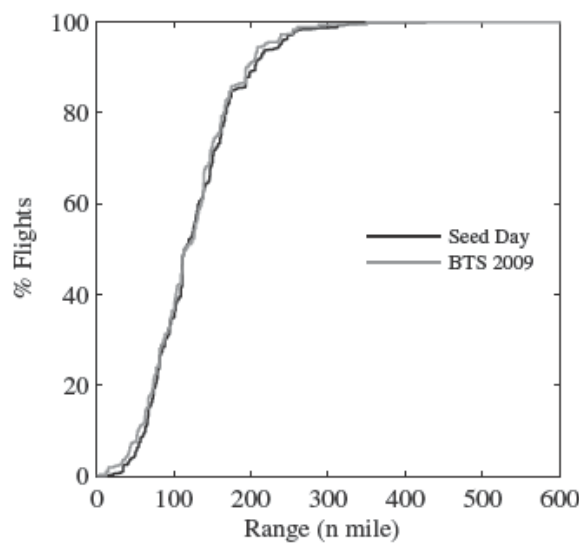

b) Range cumulative distribution

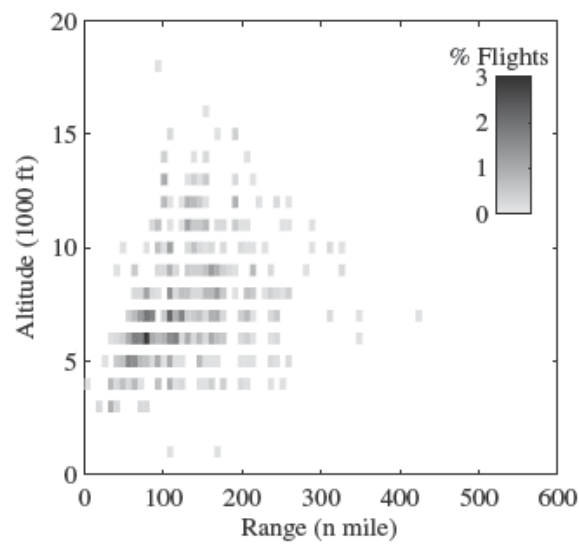

d) Seed day flight plan altitude/range density

Fig. 3 FedEx Cessna 208 payload, range, and altitude operations.

A simple comparative sizing study for a conventional cargo turboprop was performed to illustrate the potential savings of an aircraft sized to a reduced set of payload/range requirements. The cargo turboprop was assumed to have an empty weight fraction, range parameter, and crew weight similar to those of the Cessna 208; these assumptions are listed as Table 3 .

The range parameter, $R P \equiv \frac{V}{T S F C} \frac{L}{D}$, is an aggregate measure of range performance for an aircraft. The $4000 \mathrm{n}$ miles value was obtained by estimating the slope of the maximum gross weight line on the published payload range diagram for the Cessna 208 and multiplying its inverse by the published gross weight for the Cessna 208. The empty weight fraction and crew weight assumptions were also based on published data for the Cessna 208. The fuel fraction for the cargo turboprop was calculated based on a form of the Breguet range equation included as Eq. (1):

$$
W_{f} / W_{0}=1.0-\exp \left(-\frac{R}{R P}\right)
$$

The size of the vehicle required to carry the specified payload and crew with a vehicle of the appropriate empty weight and fuel fractions was calculated according to Eq. (2):

$$
W_{0}=\frac{W_{p}+W_{\mathrm{crew}}}{1.0-W_{e} / W_{0}-W_{f} / W_{0}}
$$

These assumptions and equations were used to size three notional cargo turboprop aircraft; the results are summarized in Table $\underline{4}$, the first with baseline payload/range requirements based on the capability of the Cessna 208s operated by FedEx. In addition, two vehicles were sized to the reduced requirements proposed in the preceding paragraphs. The baseline requirements resulted in a vehicle of approximately $4600 \mathrm{lb}$ empty weight; the reduced requirement sets resulted in vehicles of only 3400 and $2500 \mathrm{lb}$. Although these savings are significant, the differences would be greatly magnified if an unconventional aircraft (such as a battery electric concept) with a significantly poorer (smaller) range parameter were considered.

\section{Southwest Boeing 737-700 Operations}

A number of aircraft utilization metrics were calculated for the Southwest Airlines fleet; to match the information reported in the company's annual report, all aircraft in the fleet were used in these calculations, not just those for the 737 700. All aircraft operations reported to the BTS in 2009 were combined and divided by the monthly aircraft fleet size reported by the plane spotting data. The calculated utilization metrics are summarized in Table $\underline{5}$ along with the utilization metrics reported in the Southwest Airlines annual report. The BTS only requires reporting of transport flights, and so maintenance, training, and repositioning flights do not appear in the BTS utilization metrics. Consistent with their low cost business model, Southwest Airlines maintains a high level of utilization of aircraft and high average load factor.

Load factor is a fundamental measure of an airline's operating efficiency. For an individual flight or for multiple flights between a particular city pair, the load factor is defined as the ratio of the number of passengers transported to the number of seats available. This metric reflects the fact that the purpose of an airline is to move passengers. When an airline considers their fleet efficiency across all of the routes that they serve, they may define the load factor as the ratio of the number passenger miles transported to the number of seat miles available. This metric reflects the greater importance to an airline's efficiency of filling the long haul flights over the short hops. Passenger (or seat) mile is defined as the product of the number of passengers (or seats) and the distance for that flight. 

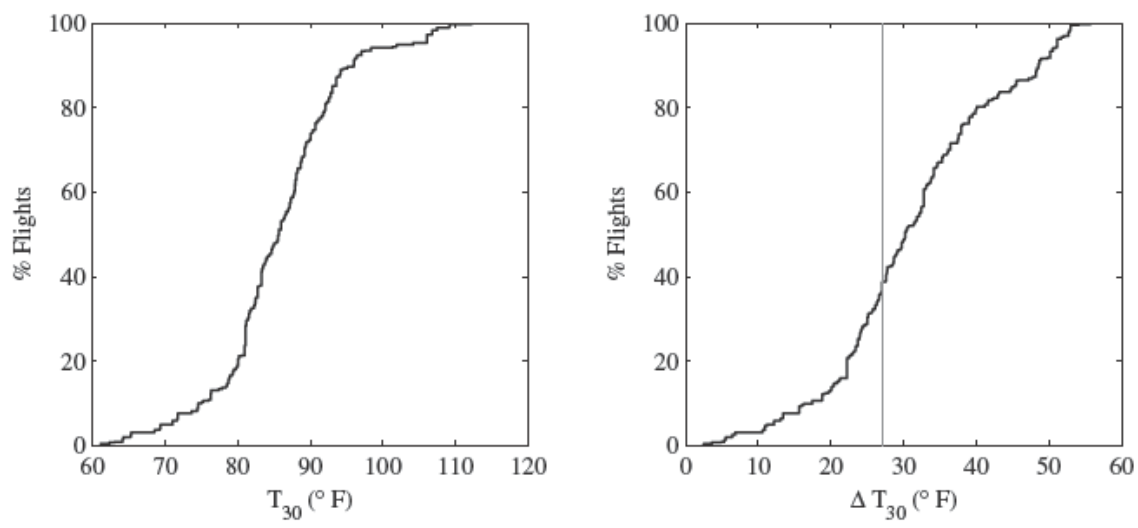

a) $T_{30}$ cumulative distribution

b) $\Delta T_{30}$ cumulative distribution
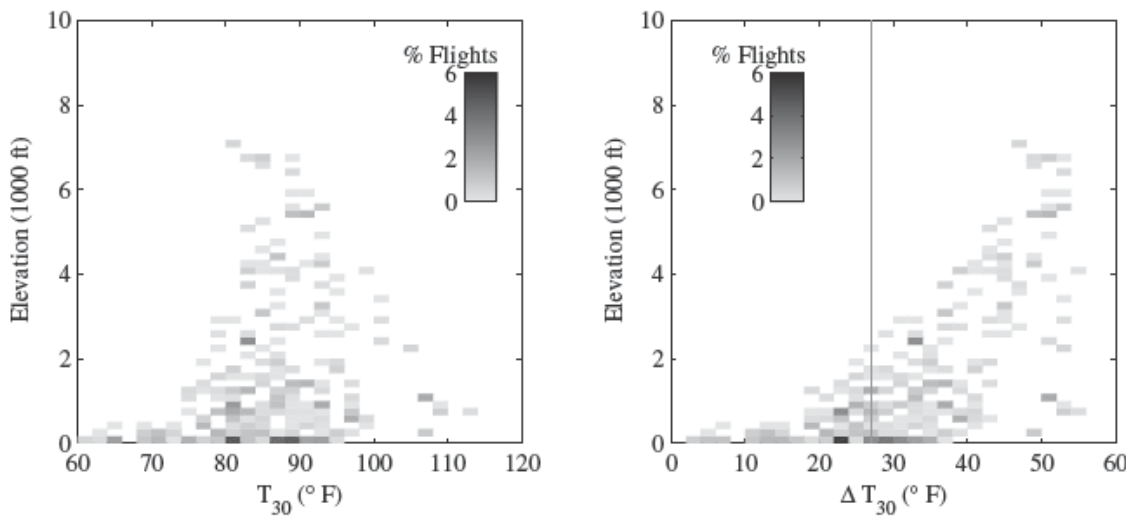

c) Elevation $/ T_{30}$ density

d) Elevation $/ \Delta T_{30}$ density

Fig. 4 FedEx Cessna 208 hottest normal high temperature at operational airports.

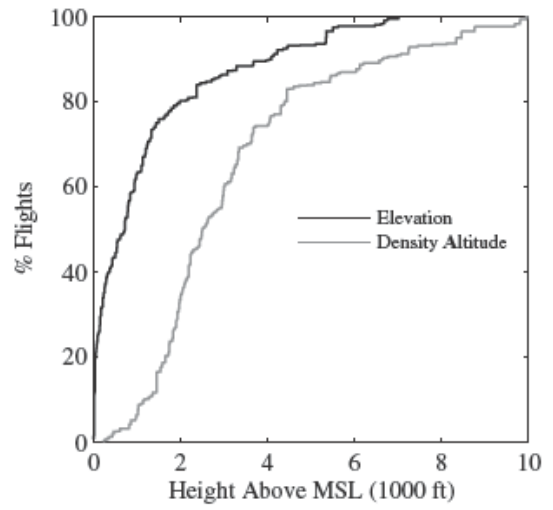

a) Elevation and density altitude distribution

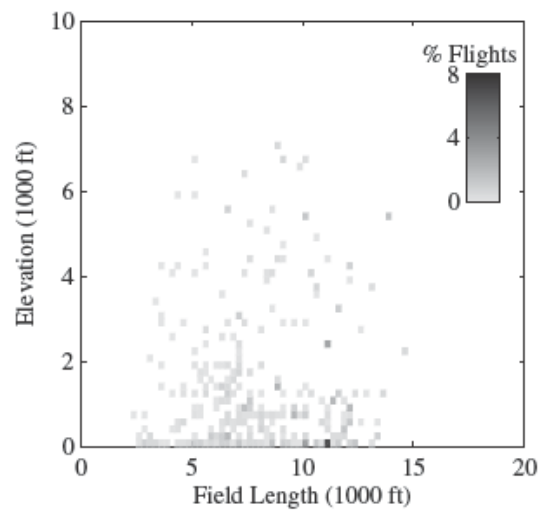

c) Elevation/field length density

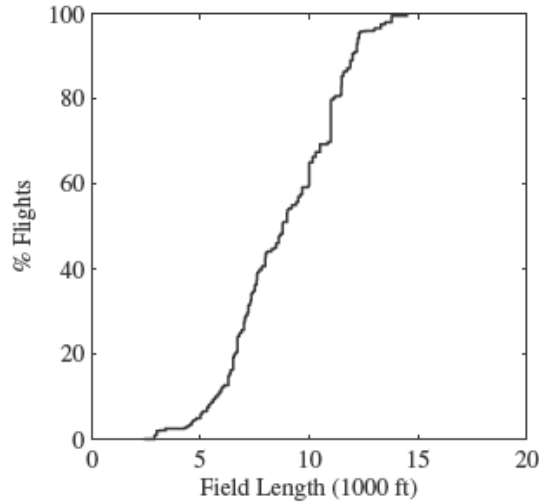

b) Field length distribution

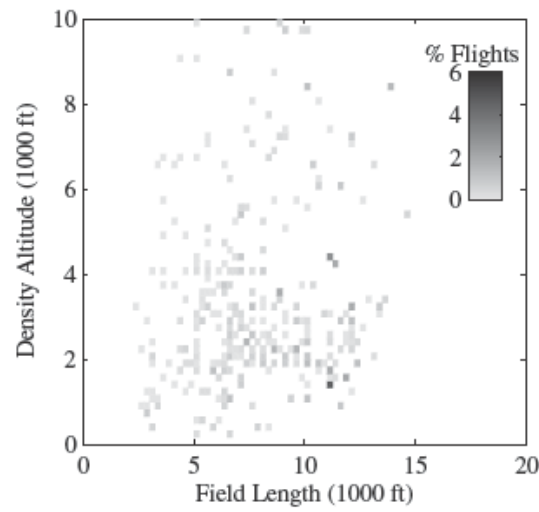

d) Density altitude/field length density

Fig. 5 FedEx Cessna 208 field operations. 
Table 3 Cargo turboprop sizing assumptions

\begin{tabular}{lccc}
\hline \hline Metric & Symbol & Units & Value \\
\hline Empty weight fraction & $W_{e} / W_{0}$ & & 0.536 \\
Range parameter & $\mathrm{RP}$ & $\mathrm{n}$ mile & 4000 \\
Crew weight & $W_{\text {crew }}$ & $\mathrm{lb}$ & 450 \\
\hline \hline
\end{tabular}

Table 4 Cargo turboprop sizing results

\begin{tabular}{lccccc}
\hline \hline Metric & Symbol & Units & Baseline & Alternate 1 & Alternate 2 \\
\hline Payload weight & $W_{p}$ & $\mathrm{lb}$ & 2640 & 2000 & 1500 \\
Range & $R$ & $\mathrm{n}$ mile & 430 & 300 & 200 \\
Gross weight & $W_{0}$ & $\mathrm{lb}$ & 8534 & 6254 & 4696 \\
Empty weight & $W_{e}$ & $\mathrm{lb}$ & 4574 & 3352 & 2517 \\
\hline \hline
\end{tabular}

Table 5 Southwest Airlines 2009 average aircraft utilization

\begin{tabular}{lcc}
\hline \hline Metric & Value & Units \\
\hline Daily flights & 5.7 & \\
Yearly flights & 2076 & \\
Daily utilization (SWA annual report) & $10: 50$ & $\mathrm{~h}: \mathrm{m}$ \\
Daily utilization (BTS ramp to ramp) & $10: 14$ & $\mathrm{~h}: \mathrm{m}$ \\
Daily utilization (BTS air time) & $8: 47$ & $\mathrm{~h}: \mathrm{m}$ \\
Yearly utilization (BTS ramp to ramp) & 3734 & $\mathrm{~h}$ \\
Yearly utilization (BTS air time) & 3205 & $\mathrm{~h}$ \\
Passenger mile load factor (SWA annual report) & 76.0 & $\%$ \\
Passenger mile load factor (BTS data) & 76.0 & $\%$ \\
Passenger load factor (BTS data) & 71.5 & $\%$ \\
\hline \hline
\end{tabular}

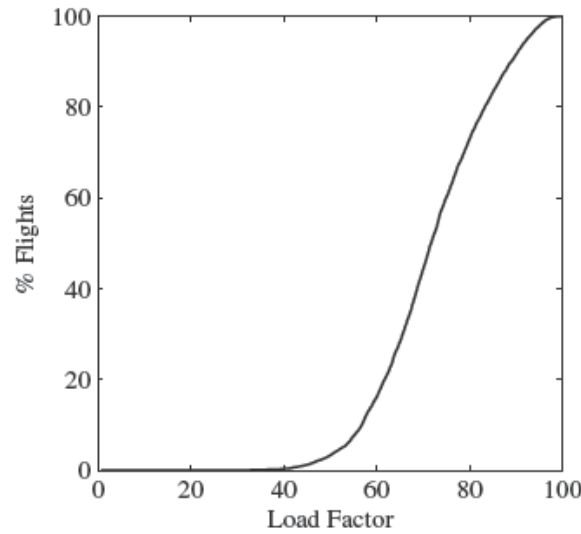

a) BTS load factor cumulative distribution

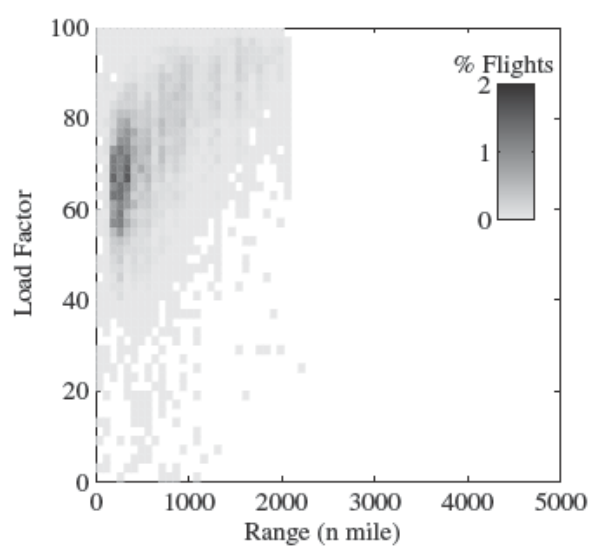

c) BTS load factor/range density
The 76.0\% load factor reported in Southwest Airlines' 2009 annual report is based on seat mile utilization rather than simple seat utilization. Both utilization metrics were calculated from the BTS data and are included in Table 5. The load factor reported in all of the subsequent figures is the traditional seat load factor.

From examining the BTS data, it does not appear that Southwest Airlines carries a significant amount of cargo or mail in addition to their passengers. Consequently, it can make sense to use the load factor as a measure of transport rather than pounds of payload. The 737300 and 737700 aircraft currently operated by Southwest carry 137 passengers in a single class layout, whereas the 737500 aircraft can carry 122 passengers. Southwest has ordered 737800 s outfitted to carry 175 passengers; the passenger capacity for the 737 MAX order has not been announced. An ECDF of load factor for Southwest's 2009737700 flights is plotted as Fig. 6a.

The distribution of distance flown by the Southwest 737 700s is plotted as an ECDF in Fig. 6b. The fleet flew less than $1500 \mathrm{n}$ miles $94 \%$ of the time, less than $1000 \mathrm{n}$ miles $85 \%$ of the time, and less than $800 \mathrm{n}$ miles $75 \%$ of the time. Although Southwest retired the last of their 737200 aircraft in 2005, the route structure and business model for the airline can be clearly traced to those aircraft; the 737200 with JT8D 9A engines operated by Southwest were capable of a $1200 \mathrm{n}$ mile range with a full payload [42].

The joint load factor/range density of the Southwest fleet based on the BTS data is plotted in Fig. 6c. There is a clear bias to a higher load factor for long range flights, which explains the discrepancy between passenger mile load factor and passenger load factor reported in Table 5. These data are also plotted as a payload/range EJPDF in Fig. $6 \overline{\mathrm{d}}$. Passenger weight was estimated by assuming a $270 \mathrm{lb}$ average weight for each passenger and their luggage; this was combined with the reported weight of any freight and mail carried to arrive at total payload weight. This figure was augmented with the published payload/range characteristics for the 737700 [42].

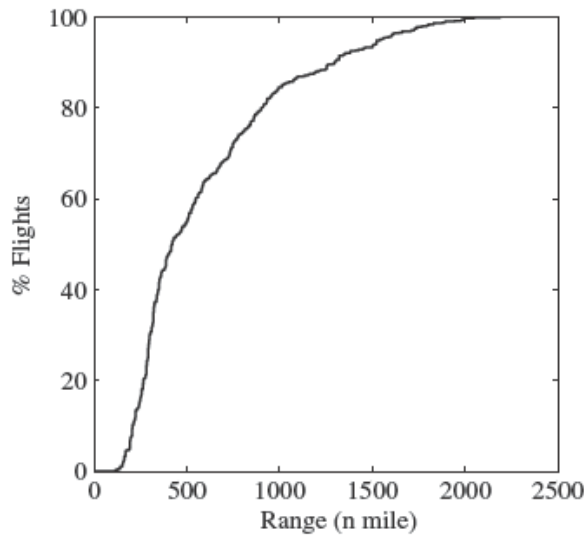

b) BTS range cumulative distribution

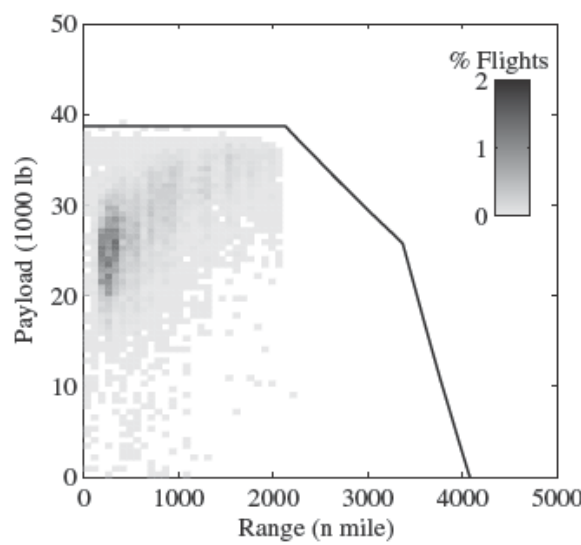

d) BTS payload/range density

Fig. 6 Southwest 737-700 load factor, range, and payload operations. 


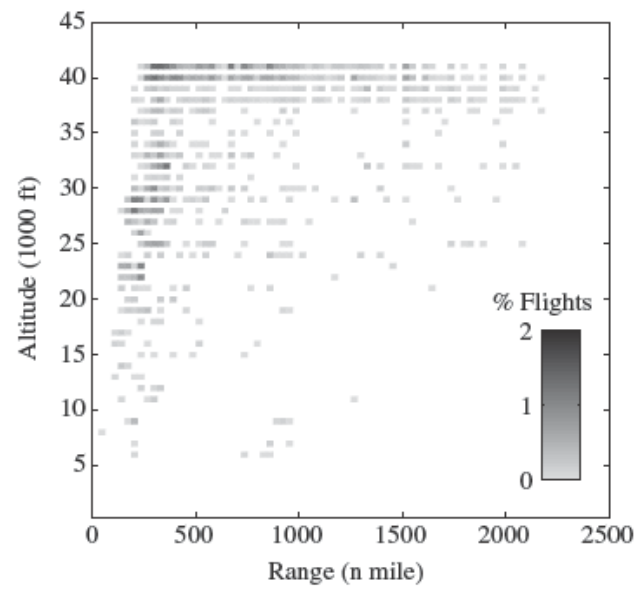

Fig. 7 Southwest 737-700 Seed Day flight plan altitude/range density.

The flight plan altitude/range operation of the Southwest Boeing 737700 fleet based on the Seed Day data was plotted as an EJPDF in Fig. 7. Although there are a significant number of flights below $30,000 \mathrm{ft}$ for ranges less than $500 \mathrm{n}$ miles, the highest density of flights are near the certification ceiling of $41,000 \mathrm{ft}$ for flights of at least $250 \mathrm{n}$ miles.

The NOAA weather normal data at weather stations nearest the airports used in the 2009BTS Southwest Airlines 737700 operations are plotted in Fig. 8. The hottest normal monthly high temperature at an airport used by Southwest is $106.8^{\circ} \mathrm{F}$. The standard $27^{\circ} \mathrm{F}$ hot day assumption is plotted as a vertical line in Figs. $8 \mathrm{~b}$ and $8 \mathrm{~d}$. Less than $26 \%$ of the airport operations have normal high temperatures below the standard $27^{\circ} \mathrm{F}$ hot day assumption. A $40^{\circ} \mathrm{F}$ hot day assumption

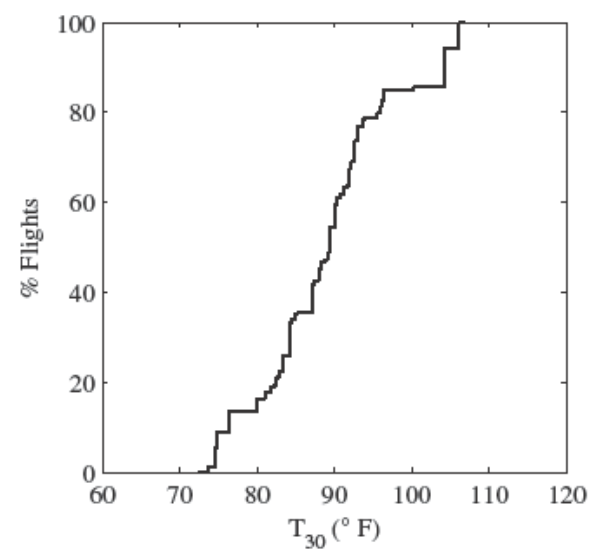

a) $T_{30}$ cumulative distribution

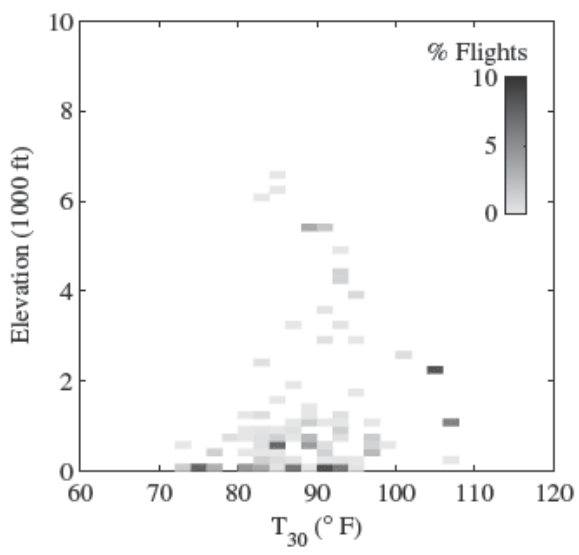

c) Elevation $/ T_{30}$ density would include $75 \%$ of the airport operations; a $52^{\circ} \mathrm{F}$ assumption would be required to include $90 \%$ of operations.

The range of airfields used by the Southwest Airlines Boeing 737700 fleet were explored in Fig. 9. The runway length at airfields used by the BTS flights were obtained from the combined runway length data set. The airfield elevation and runway length are plotted as ECDFs in Figs. 9a and 9b, respectively. The hot day density altitude is also included in Fig. $9 \mathrm{~d}$.

The joint density of the elevation/runway length operation of the Southwest 737700 fleet is plotted as an EJPDF in Fig. 9c; the corresponding density altitude/runway length EJPDF is plotted in Fig. 9d. Most flights occur from airports at low elevation, and there is a significant bias such that high elevation airfields that are used are likely to have long runways. Southwest often operates out of secondary airports in major cities (Dallas Love, Houston Hobby, Chicago Midway); the shorter runways of these airports should be considered when designing a replacement aircraft.

\section{Southwest Boeing 737-700 Replacement Proposed Requirements}

As with the Cessna 208 discussed earlier, a designer considering the design of a Boeing 737700 replacement with Southwest as a launch customer may consider designing the replacement aircraft to a set of requirements less than the 737 700's full capabilities. Such a vehicle may be smaller and cheaper than the aircraft it replaces, or the reduced set of requirements may enable consideration of alternative advanced concept aircraft, which may not feasibly be designed to match the 737 700's performance in every way.

In becoming the launch customer for the 737 MAX, Southwest ordered 150 aircraft \pm . If an aircraft was expected to replace all of the 737300 and 737700 aircraft in the Southwest fleet, orders could approach 600 aircraft, or more if the airline continues to grow.

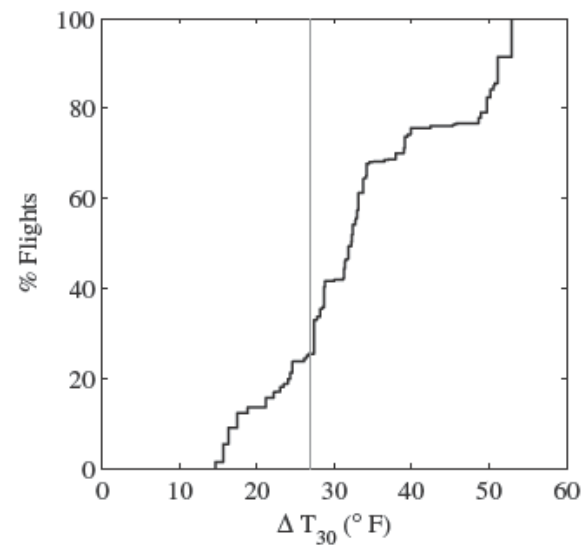

b) $\Delta T_{30}$ cumulative distribution

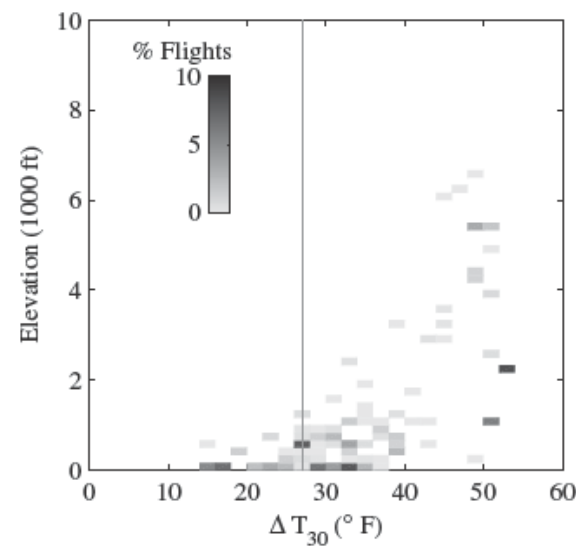

d) Elevation $/ \Delta T_{30}$ density

Fig. 8 Southwest B737-700 hottest normal high temperature at operational airports. 


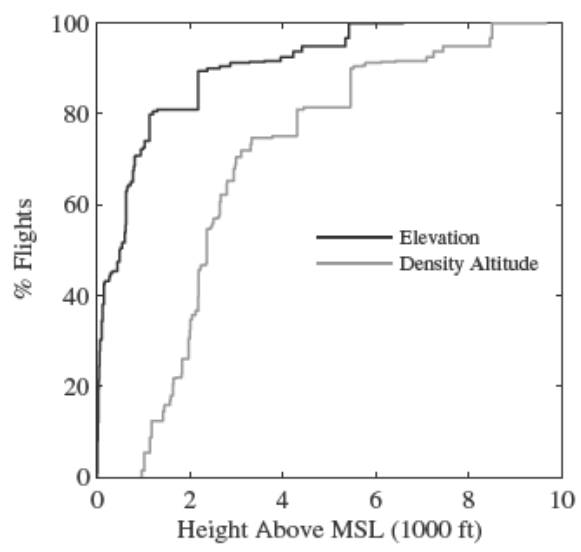

a) Elevation and density altitude distribution

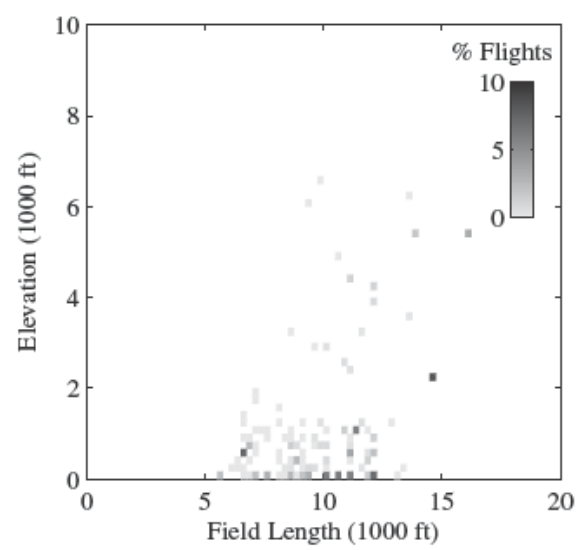

c) Elevation/field length density

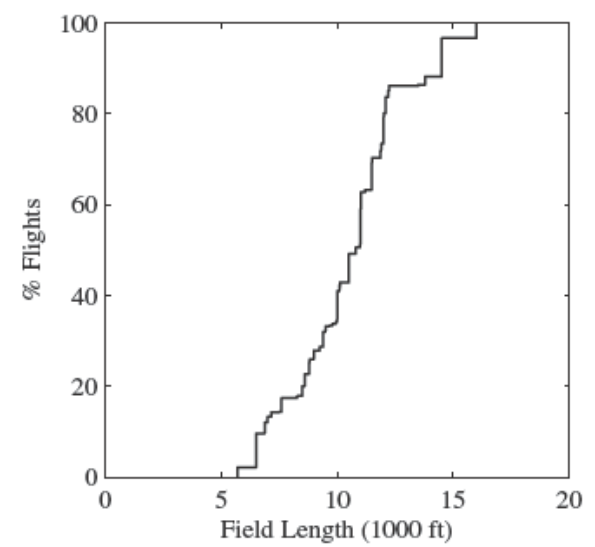

b) Field length distribution

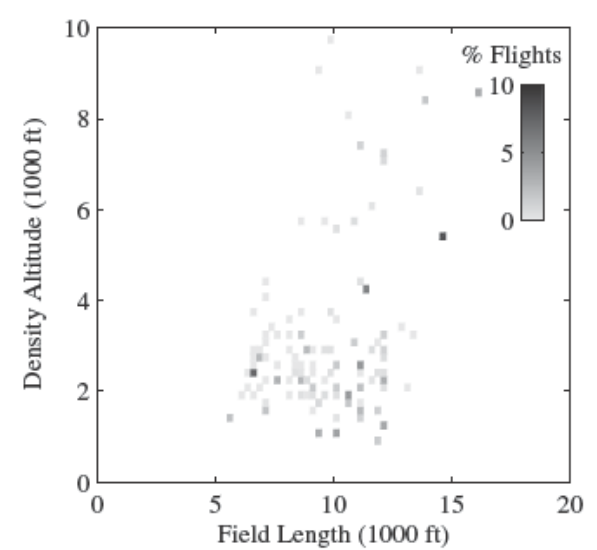

d) Density altitude/field length density

Fig. 9 Southwest 737-700 field operations.

Southwest's operations demand high utilization; the aircraft should be able to sustain six flights per day and will accumulate approximately 4000 flight hours per year. The aircraft should be sized to match the 137 seat capacity of the aircraft it replaces (or possibly the 122 seat capacity of the Southwest 737500 fleet) the performance of the aircraft must not limit the load factor to less than $100 \%$. Depending on the reduction in capability required, the aircraft could be designed to $1500,1200,1000$, or even $800 \mathrm{n}$ miles.

Operation out of Chicago Midway's $6522 \mathrm{ft}$ runway at $620 \mathrm{ft}$ elevation is likely to be most critical. Chicago Midway's greatest normal monthly high temperature is $84.2^{\circ} \mathrm{F}$, which corresponds to $27.4^{\circ} \mathrm{F}$ above standard conditions, which is remarkably close to the common hot day assumption. This hot day condition results in a $2366 \mathrm{ft}$ density altitude. Although Southwest does operate out of airports with much higher density altitudes, those airports typically have much longer runways.

In a recent study similar in spirit to this paper, Martinez Val et al. [43] worked to quantify the cost of the mismatch between the capability and operational use of aircraft across the commercial transport fleet.

\section{Conclusions}

It is possible to conduct sophisticated simulations and trade studies when establishing the requirements for a proposed aircraft design, but such studies are often beyond the scope of the conceptual aircraft design process. It is expected that military operators and commercial manufacturers thoroughly study the requirements before committing to develop a vehicle. However, industrial teams performing quick look studies as well as students or researchers engaged in aircraft design seldom have the authority, skills, resources, or time to conduct sophisticated requirements trade studies. Examining the operational use of aircraft provides a simplified means of quantitatively studying aircraft requirements.
Aircraft operators and manufacturers are expected to have exten sive operational databases for their fleets and products; however, much information about the operation of commercial aircraft can be discerned from publicly available sources. The operational use of two commercial aircraft was studied from the standpoint of guiding the design of their replacement aircraft. This understanding of how the operators use the aircraft may enable their replacements to be smaller or less expensive than current aircraft, or it may enable the design of unconventional replacements, which might be otherwise unfeasible.

An aircraft designed to replace the utility rather than the capability of another aircraft attempts to trade unused margin for a smaller, less expensive design. If the required use of the new aircraft unexpectedly changes, that unused margin could become very desirable. If the new aircraft is similar in technology to the replaced aircraft, the changes in the capability margin will most likely be small, as will the savings realized by matching utility over capability. On the other hand, if the new aircraft's technology is significantly different than the replaced aircraft, the changes in the capability margin may be large. Further, the savings realized by matching utility instead of capability may be the key to a feasible or viable design.

\section{Acknowledgments}

This work has been performed while the author served as a member of the Aeronautics Systems Analysis Branch at NASA Langley Research Center, through an Intergovernmental Personnel Act agreement. Thanks to Samuel J. Frame, the Spring 2011 California Polytechnic State University Statistics Consultant, for various helpful discussions related to the preparation and presentation of these data.

\section{References}

[1] Wood, K. D., Airplane Design, 7th ed., Purdue Univ., Lafayette, Indiana, 1943, pp. 1:1 1:21. 
[2] Corning, G., Airplane Design, Edwards Brothers, Inc., Ann Arbor, MI, 1953, pp. 1:1 1:7.

[3] Anon., "System Engineering Management," U.S. Air Force Rept. MIL STD 499, 17 July 1969.

[4] Nicolai, L. M., and Carichner, G., Fundamentals of Aircraft and Airship Design, AIAA, Reston, VA, 2010, pp. 130.

[5] Mavris, D. N., and DeLaurentis, D., "Methodology for Examining the Simultaneous Impact of Requirements, Vehicle Characteristics, and Technologies on Military Aircraft Design," 22nd Congress of the International Council on the Aeronautical Sciences (ICAS), International Council on the Aeronautical Sciences Paper 2000 1.4.4, 28 Aug. 1 Sept. 2000.

[6] Drake, M., "Conceptual Design of The Boeing 787," AIAA Aircraft Design Technical Committee Meeting, Orlando, FL, 5 Jan. 2010.

[7] Briceno, S., "A Game Based Decision Support Methodology for Competitive Systems Design," Ph.D. Dissertation, Aerospace Engineering, Georgia Inst. of Technology, Atlanta, GA, 2008.

[8] Morrison, J. K., "Game Theory Analysis of Aircraft Manufacturer Innovation Strategies in the Face of Increasing Airline Fuel Costs," M.S. Thesis, Engineering Systems Division, Technology and Policy Program, Massachusetts Inst. of Technology, Boston, MA, June 2011.

[9] Baker, A. P., Mavris, D. N., and Schrage, D. P., "Assessing the Impact of Mission Requirements, Vehicle Attributes, Technologies and Uncer tainty in Rotorcraft System Design," American Helicopter Society 58th Annual Forum, Montreal, Canada, American Helicopter Society International, Alexandria, VA, 1113 June 2002, pp. 303312.

[10] Soban, D. S., and Mavris, D. N., "The Need for a Military System Effectiveness Framework The System of Systems Approach," 1st AIAA, Aircraft, Technology Integration, and Operations Forum, AIAA Paper 2001 5226, 1618 Oct. 2001.

[11] Viken, J., Downs, M., Dollyhigh, S., Guerreiro, N., and Fenbert, J., Scenarios for the NASA Airspace Systems Program, 27 Sept. 2009.

[12] Penny, S., Lewis, T., Hoffman, B., White, T., and Krozel, J., "Cluster Analysis for the Annualization of ACES Simulated NAS Metrics," Metron Aviation, Dulles, VA, 31 Jan. 2009.

[13] Anon., "T 100 Traffic Reporting Guide," U.S. Dept. of Transportation, Research and Innovative Technology Administration, Bureau of Transportation Statistics: Office of Airline Information, 2010.

[14] “T 1002009 Traffic Segment Data for All Carriers," U.S. Dept. of Transportation, Research, and Innovative Technology Administration, Bureau of Transportation Statistics: Office of Airline Information, 22 April 2011.

[15] Megginson, D., "OurAirports Database" [online database], http://www .ourairports.com/data/airports.csv [retrieved 21 April 2011].

[16] "Airport Data \& Contact Information," Federal Aviation Administra tion, 7 June 2011.

[17] "Canada Flight Supplement," NAV CANADA, Ottawa, Ontario, 6 May 2011.

[18] "Canada Water Aerodrome Supplement," NAV CANADA, 11 March 2011.

[19] "ST3400 TAWS Airport Database" [online database], http://www.sandel .com/xls.php/ST3400 Airports 1102.xls [retrieved 1 June 2011]

[20] Arguez, A., Durre, I., Applequist, S., Vose, R. S., Squires, M. F., Yin, X., Heim, R. R., and Oven, T. W., "NOAA's 19812010 U.S. Climate Normals: An Overview," Bulletin of the American Meteorological Society, Vol. 93, 2012, pp. 16871697. doi:10.1175/BAMS D 1100197.1

[21] "Southwest Airlines Annual Report to Shareholders," Southwest Airlines, Dallas, TX, 1994, http://southwest.investorroom.com/ download/1994+Annual+Report.pdf [retrieved 19 August 2011].
[22] "Southwest Airlines Annual Report to Shareholders," Southwest Airlines, Dallas, TX, 1995, http://southwest.investorroom.com/ download/1995+Annual+Report.pdf [retrieved 19 August 2011]

[23] "Southwest Airlines Annual Report to Shareholders," Southwest Airlines, Dallas, TX, 1996, http://southwest.investorroom.com/ download/1996+Annual+Report.pdf [retrieved 19 August 2011].

[24] "Southwest Airlines Annual Report to Shareholders," Southwest Airlines, Dallas, TX, 1997, http://southwest.investorroom.com/ download/1997+Annual+Report.pdf [retrieved 19 August 2011].

[25] "Southwest Airlines Annual Report to Shareholders," Southwest Airlines, Dallas, TX, 1998, http://southwest.investorroom.com/ download/1998+Annual+Report.pdf [retrieved 19 August 2011].

[26] "Southwest Airlines Annual Report to Shareholders," Southwest Airlines, Dallas, TX, 1999, http://southwest.investorroom.com/ download/1999+Annual+Report.pdf [retrieved 19 August 2011].

[27] "Southwest Airlines Annual Report to Shareholders," Southwest Airlines, Dallas, TX, 2000, http://southwest.investorroom.com/ download/2000+Annual+Report.pdf [retrieved 19 August 2011]

[28] "Southwest Airlines Annual Report to Shareholders," Southwest Airlines, Dallas, TX, 2001, http://southwest.investorroom.com/ download/2001+Annual+Report.pdf [retrieved 19 August 2011].

[29] "Southwest Airlines Annual Report to Shareholders," Southwest Airlines, Dallas, TX, 2002, http://southwest.investorroom.com/ download/2002+Annual+Report.pdf [retrieved 19 August 2011].

[30] "Southwest Airlines Annual Report to Shareholders," Southwest Airlines, Dallas, TX, 2003, http://southwest.investorroom.com/ download/2003+Annual+Report.pdf [retrieved 19 August 2011].

[31] "Southwest Airlines Annual Report to Shareholders," Southwest Airlines, Dallas, TX, 2004, http://southwest.investorroom.com/ download/2004+Annual+Report.pdf [retrieved 19 August 2011].

[32] "Southwest Airlines Annual Report to Shareholders," Southwest Airlines, Dallas, TX, 2005, http://southwest.investorroom.com/ download/2005+Annual+Report.pdf [retrieved 19 August 2011].

[33] "Southwest Airlines Annual Report to Shareholders," Southwest Airlines, Dallas, TX, 2006, http://southwest.investorroom.com/ download/2006+Annual+Report.pdf [retrieved 19 August 2011].

[34] "Southwest Airlines Annual Report to Shareholders," Southwest Airlines, Dallas, TX, 2007, http://southwest.investorroom.com/ download/2007+Annual+Report.pdf [retrieved 19 August 2011].

[35] "Southwest Airlines Annual Report to Shareholders," Southwest Airlines, Dallas, TX, 2008, http://southwest.investorroom.com/ download/2008+Annual+Report.pdf [retrieved 19 August 2011].

[36] "Southwest Airlines Annual Report to Shareholders," Southwest Airlines, Dallas, TX, 2009, http://southwest.investorroom.com/ download/2009+Annual+Report.pdf [retrieved 19 August 2011].

[37] "Southwest Airlines Annual Report to Shareholders," Southwest Airlines, Dallas, TX, 2010, http://southwest.investorroom.com/ download/2010+Annual+Report.pdf [retrieved 19 August 2011].

[38] FedEx Historical Stat Book FY 1998 FY 2005, Memphis, TN, 2005.

[39] FedEx Historical Stat Book FY 2005 FY 2008, Memphis, TN, 2008.

[40] FedEx Q2 FY11 Statistical Book, Memphis, TN, 2011.

[41] Verbrugge, S., and Langevoort, A., airlinerlist.com, 14 June 2011, http:// www.airlinerlist.com/.

[42] "737 Airplane Characteristics for Airport Planning," The Boeing Co., Seattle, WA, March 2011

[43] Martinez Val, R., Roa, J., Perez, E., and Cuerno, C., "Effects of the Mismatch Between Design Capabilities and Actual Aircraft Utilization," Journal of Aircraft, Vol. 48, No. 6, 2011, pp. 19211927. doi:10.2514/1.C031348 